\title{
Long-Term Safety and Efficacy of Sitagliptin for Type 2 Diabetes Mellitus in Japan: Results of a Multicentre, Open-Label, Observational Post-Marketing Surveillance Study
}

\author{
Ken Yoshikawa · Akira Tsuchiya • Tomoyuki Kido • Tomohiro Ota • \\ Keiko Ikeda · Mika Iwakura · Yoshikazu Maeda · Shinichiroh Maekawa
}

Received: January 27, 2020 / Published online: April 18, 2020

(C) The Author(s) 2020

\begin{abstract}
Introduction: A post-marketing surveillance (PMS) study was conducted to confirm the longterm risk-benefit profile of sitagliptin administered to Japanese patients with type 2 diabetes mellitus (T2DM) under real-world conditions.

Methods: This prospective, multicentre, openlabel PMS collected data from 3326 patients receiving sitagliptin according to the approved indication during the case registration period (July 2010-June 2012; observation period, 3 years). Safety was assessed via collection of data on adverse drug reactions (ADRs), estimated glomerular filtration rate (eGFR) and cardiovascular events whereas efficacy was
\end{abstract}

Enhanced Digital Features To view digital features for this article go to https://doi.org/10.6084/m9.figshare. 11961306.

Electronic supplementary material The online version of this article (https://doi.org/10.1007/s12325020-01293-2) contains supplementary material, which is available to authorized users.

K. Yoshikawa $(\bowtie) \cdot$ A. Tsuchiya · T. Kido

Pharmacovigilance Division, Ono Pharmaceutical

Co., Ltd., Osaka, Japan

e-mail: k.yoshikawa@ono.co.jp

T. Ota $(\bowtie) \cdot$ K. Ikeda · M. Iwakura · Y. Maeda .

S. Maekawa

Japan Pharmacovigilance, MSD K.K., Tokyo, Japan

e-mail: tomohiro.ota@merck.com assessed via changes in glycated hemoglobin (HbA1c).

Results: In 3265 patients evaluated for safety, 270 ADRs occurred in 207 (6.3\%) patients overall. Metabolism and nutrition disorders were the most common class of ADRs, occurring in 58 patients overall (53 non-serious, 5 serious) with hypoglycaemia (17 patients, $0.52 \%$ ) the most common ADR. In patients with eGFR > $90 \mathrm{~mL} / \mathrm{min} / 1.73 \mathrm{~m}^{2}$ at baseline (mean $\pm \mathrm{SD}$, $\left.106.42 \pm 18.11 \mathrm{~mL} / \mathrm{min} / 1.73 \mathrm{~m}^{2}, n=584\right)$, eGFR declined by $11.83 \pm 17.53 \mathrm{~mL} / \mathrm{min} / 1.73 \mathrm{~m}^{2}$ $(P<0.0001 ; n=360)$ over the observation period whereas eGFR appeared to be relatively maintained in patients with lower baseline eGFR levels. Cardiovascular events were infrequent [occurring in 4 of $84(4.76 \%)$ patients at high cardiovascular risk] with no distinct features in this Japanese population and the cumulative incidence $[8.42 \%(3.12-21.70)$ at 36 months; $n=32$ ] was similar to that noted in previous studies involving sitagliptin. In patients evaluated for efficacy, the overall change in $\mathrm{HbA1c}$ from baseline to final evaluation was mean $\pm \mathrm{SD}-0.68 \pm 1.34 \% \quad(P<0.0001$, $n=2070$ ). Reductions in HbA1c tended to be greater in younger patients and patients with higher body mass index (BMI) and HbA1c values at the start of administration.

Conclusion: Long-term sitagliptin administration in the routine clinical practice setting is associated with good efficacy, including as monotherapy, with no additional safety concerns. 
Keywords: Efficacy; Observational study; Postmarketing surveillance; Safety; Sitagliptin; Type 2 diabetes mellitus

\section{Key Summary Points}

Why carry out this study?

In Japan, post-marketing surveillance studies (PMS) are required to verify the safety and efficacy of agents in clinical practice settings over long-term periods.

This prospective, open-label PMS was designed to confirm the long-term risk-benefit profile of sitagliptin administered to Japanese patients with type 2 diabetes mellitus under real-world conditions.

\section{What was learned from this study?}

In Japanese patients, sitagliptin maintains effective glycaemic control while reducing the number of concomitant medications in association with a low rate of drugrelated adverse reactions.

The real-world safety of sitagliptin is consistent with the known safety profile noted in clinical studies of Japanese patients, and there is no apparent increased risk of cardiovascular events compared with non-Japanese patients.

\section{INTRODUCTION}

Type 2 diabetes mellitus (T2DM) is becoming increasingly prevalent in Japan with recent Japanese Ministry of Health, Labour and Welfare (MHLW) estimates indicating that the prevalence of T2DM in Japan increased from approximately 9.5 million in 2012 to 10.0 million in $2016[1,2]$. Primarily as a result of an aging population, but also in response to greater adoption of Western dietary patterns, the prevalence of diabetes is predicted to continue to increase in Japan [3, 4]. Evidence strongly indicates that the risk of both microvascular and macrovascular complications increases with the duration and severity of hyperglycaemia $[5,6]$. Such complications have been repeatedly shown to be instrumental in reducing the quality of life and, especially in the case of cardiovascular disease, life expectancy of patients with T2DM $[7,8]$.

Several studies have established the importance of tight glycaemic control in reducing microvascular complications of T2DM [9]. However, findings from several large-scale studies have suggested a more nuanced view of the benefits of intensive blood glucose lowering in reducing macrovascular complications [9-13]. For this reason, latest guidance has stressed the importance of a patient-centred approach to balance the benefits of glycaemic control with potential risks and consider the safety profile of glucose-lowering medications against patient-specific characteristics, including age and health status [14].

Dipeptidyl peptidase 4 (DPP4) inhibitors prolong the effect of incretin hormones [especially glucagon-like peptide 1 (GLP-1) and glucose-dependent insulinotropic polypeptide (GIP)] in stimulating insulin release and decreasing glucagon secretion in a blood glucose-dependent manner. DPP4 inhibitors have demonstrated sufficient efficacy in lowering blood glucose with a lower risk of hypoglycaemia compared with other insulin secretagogues such as sulfonylureas [15]. Owing to their well-balanced benefit to risk characteristics, DPP4 inhibitors are currently the most commonly prescribed oral hypoglycaemic agents in Japan [16].

Sitagliptin (Januvia $^{\circledR}$, MSD K.K., Tokyo, Japan; Glactiv ${ }^{\circledR}$, Ono Pharmaceutical Co., Ltd, Osaka, Japan) was the first DPP4 inhibitor to be approved in Japan. To support the marketing authorisation of sitagliptin in Japan, multiple phase II/III clinical studies have been submitted to the Japanese Pharmaceuticals and Medical Devices Agency (PMDA). These studies have verified the effectiveness of sitagliptin for each indication [17-23], and are supported by sustained improvements noted in open-label extension studies over periods of 40 weeks. In terms of safety, sitagliptin has shown an 
incidence of adverse events similar to that of placebo throughout these studies. These positive efficacy and safety results have been subsequently confirmed in large-scale observational studies conducted in Japanese patients with T2DM [24, 25]. However, the typical duration of clinical and observational studies does not permit assessment of certain events (e.g. cardiovascular events, malignancies) that often require longer periods to become apparent and more recent data further to that from studies are currently available. Hence, the MHLW in Japan requires marketing authorisation holders to submit post-marketing surveillance studies (PMS) and other surveillance activities to the PMDA during the re-examination period to verify safety and efficacy of agents in clinical practice settings over periods that allow assessment of long-term events [26].

As part of the commitment to demonstrate that sitagliptin has continued to maintain a good benefit to risk profile in clinical practice settings, MSD K.K., Tokyo, Japan and Ono Pharmaceuticals conducted various drug use results surveys, including a large, long-term survey of Japanese patients with T2DM routinely treated with sitagliptin in clinical practice. Here, we report the results of 3-year observations including over 3000 patients with T2DM treated with sitagliptin under real-world conditions in Japan.

\section{METHODS}

\section{Study Design and Patients}

This prospective, multicentre, open-label PMS was designed to investigate the long-term safety and efficacy of sitagliptin in Japanese patients with T2DM over an observation period of 3 years. From July 2010 to June 2012, patients were registered using a prospective central registration method. The total surveillance period for the drug-use results surveys was from July 2010 to March 2016 (investigation period, 5.75 years).

According to the approved indication, patients were included if they were receiving sitagliptin because of insufficient response to dietary therapy and/or exercise therapy only or dietary/exercise therapy in conjunction with one of the following antihyperglycaemic agents: sulfonylureas, thiazolidinediones, biguanides, $\alpha$-glucosidase inhibitors, or insulin preparations. In contrast, patients were excluded if they had poor prognosis diseases (e.g. malignant tumours), developed stroke or myocardial infarction within a month before initiation of sitagliptin therapy, or were considered inappropriate for long-term observation by the physician.

This PMS activity was conducted in accordance with Good Post-Marketing Study Practice, MHLW Ordinance Number 171, December 20, 2004 [27]. The study protocol was reviewed and approved by the Japanese regulatory authority prior to study initiation. Accordingly, informed consent and institutional review board approval were not required.

\section{Safety Outcome Measures}

For the safety evaluation, adverse events (AEs) were collected and classified according to the ICH Medical Dictionary for Regulatory Activities Japanese edition (MedDRA), Japanese Version 20.0. We mainly reported adverse drug reactions (ADRs) that were evaluated from AEs and that were coded using the same MedDRA preferred term (PT), according to lowest level terms, and that occurred multiple times in the same patient were tabulated as one reaction per patient. ADRs of special interest, which include ADRs considered as serious in the Japanese approved package insert and broadly correspond to those listed under the Warnings and Precautions section of the US package insert, were considered separately. In relation to most of these ADRs, Standardised MedDRA Queries (SMQs) were used in the identification and retrieval of potentially relevant reactions, including acute pancreatitis and bowel obstruction. However, for musculoskeletal disorders, gastrointestinal disorders (excluding acute pancreatitis and bowel obstruction) and infectious diseases, the MedDRA SOC category was used whereas, for cases of pemphigoid, the MedDRA PT was used to extract events. 
For evaluation of cumulative incidence, cardiovascular events noted as serious AEs in the high-risk population were assessed. Information regarding the cardiovascular events was also evaluated and described from a population selected using criteria similar to those used in the Trial Evaluating Cardiovascular Outcomes with Sitagliptin (TECOS) study [28]. Specifically, patients selected for the cardiovascular event assessment were over 50 years of age with a glycated hemoglobin (HbA1c) level of 6.5-8.0\% as well as a history of antidiabetic medication use before administration of sitagliptin and myocardial infarction, angina or cerebral haemorrhage.

As part of the safety assessment, changes in estimated glomerular filtration rate (eGFR) were recorded at regular (generally 3-monthly) intervals throughout the administration period and these changes were further considered for stratifications based on both eGFR and age at baseline.

\section{Efficacy Outcome Measures}

For the efficacy evaluation, changes in HbA1c throughout the observation period were examined for the overall population as well as in subgroups based on body mass index (BMI) and age. In addition, changes in $\mathrm{HbA} 1 \mathrm{c}$ from before the start of administration (baseline) to 36 months after administration were calculated for patients with available data according to HbA1c level at the start of administration $(<6.0 \%, 6.0 \%$ to $<7.0 \%, 7.0 \%$ to $<8.0 \%$, $\geq 8.0 \%)$.

\section{Statistical Analysis}

Summary statistics were developed for baseline characteristics, frequency of ADRs, eGFR and HbA1c levels. In general, categorical data were summarized by frequency and percentage, and continuous data were summarized using descriptive statistics. Assessments were conducted before the start of the administration period (baseline) and at 1 month, 3 months and then 3-monthly intervals until 36 months after the start of administration and at the time of final evaluation. For changes in eGFR and HbA1c, significance levels were calculated at each assessment for patients with corresponding data at the predose assessment and at each assessment time point via the paired $t$ test, with statistical significance set at $P<0.05$. The cumulative incidence of ADRs and cardiovascular events was shown using Kaplan-Meier plots. Statistical analysis was performed using SAS 9.3 (SAS ${ }^{\circledR}$, Cary, NC, USA).

\section{RESULTS}

\section{Patient Disposition and Characteristics}

The disposition of survey patients during the observation and data collection period is shown in Fig. 1. Overall, from a total of 3492 registered patients, the survey collected information related to long-term use for a total of 3326 patients from 886 facilities. Data were evaluated for 3265 patients in the safety analysis set and 2776 patients in the efficacy analysis set.

Baseline characteristics of included patients are shown in Table 1 . Approximately $60 \%$ of patients were male and the mean age was approximately 64 years in both the safety and efficacy analysis set. Overall, hyperlipidaemia and hypertension were the most common complications, occurring in $58.7 \%$ and $54.3 \%$ of patients, respectively. At the start of administration, $67.9 \%$ of patients were receiving one or more agents for diabetes. In terms of the relationship between sitagliptin and previous agents for diabetes, $31.6 \%$ of patients were treatment-naïve, $29.8 \%$ of patients had switched therapy from a pretreatment agent and $38.1 \%$ of patients received sitagliptin in addition to pretreatment agent(s). Sitagliptin was initially used as a single agent in $40.6 \%$ of patients and as part of a combination in $59.0 \%$ of patients. However, the number of patients receiving concomitant drugs decreased from as early as the first month after sitagliptin administration and this continued over the course of observation such that, at 36 months, $98.1 \%$ of patients were receiving sitagliptin alone for diabetes (Fig. 2). Sulfonylureas and biguanides were the most commonly used concomitant 


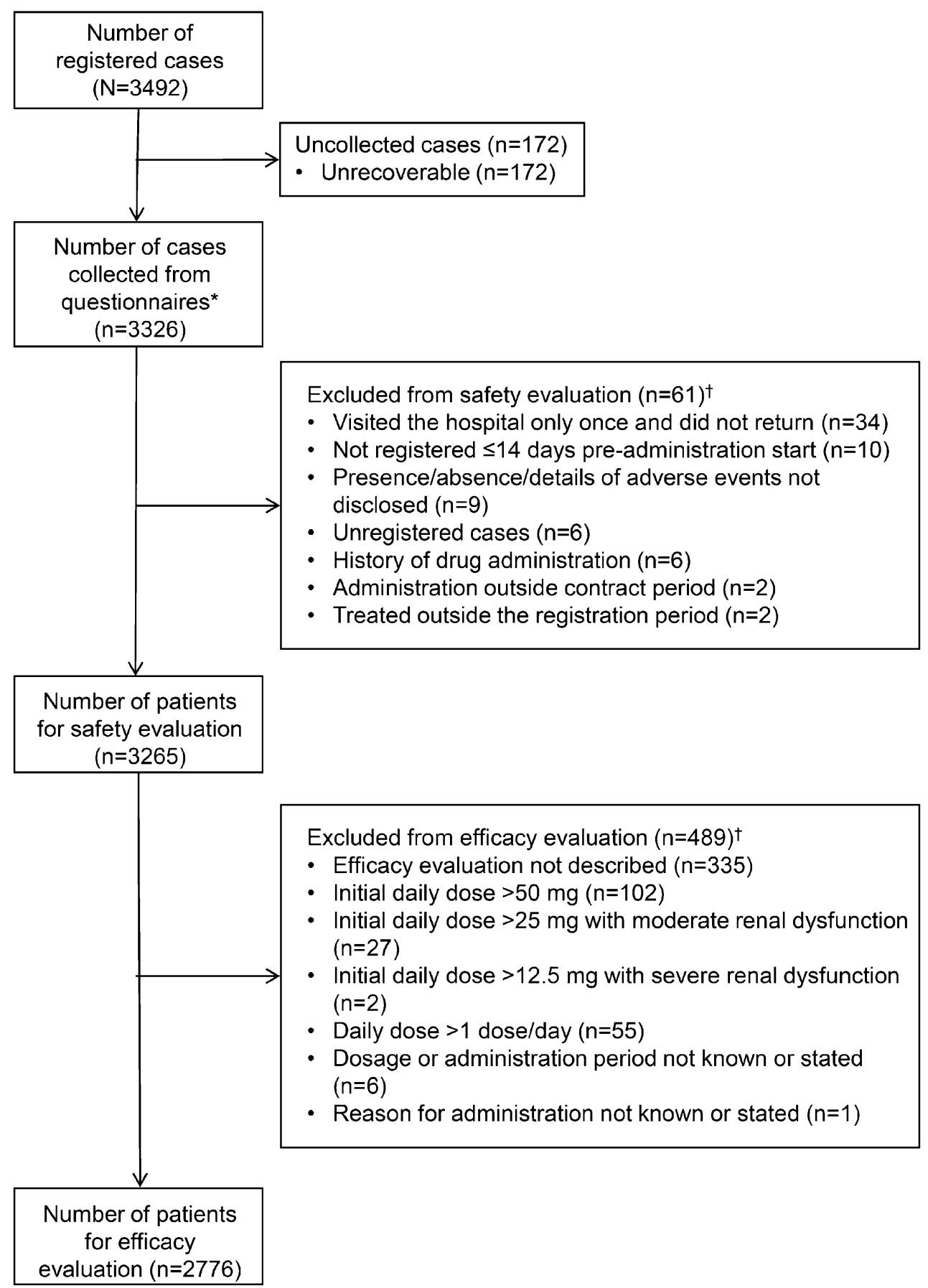

Fig. 1 Number of cases collected from questionnaires. Including 6 unregistered cases (questionnaires collected without registration). ${ }^{\dagger}$ If there were multiple reasons for exclusion, the results were tabulated for each reason

medications during the course of sitagliptin treatment (sulfonylureas, $44.3 \%$ of patients; biguanides $32.6 \%$ of patients; Table 1 ). In the safety analysis set, sitagliptin was administered for a median (IQR) period of 1034.5 days (372.5-1111.0) and $41.8 \%$ of patients were treated for more than 3 years. 
Table 1 Baseline characteristics of registered patients evaluated for safety and efficacy

\begin{tabular}{|c|c|c|}
\hline $\begin{array}{l}\text { Background } \\
\text { characteristic }\end{array}$ & $\begin{array}{l}\text { Safety } \\
(N=3265)\end{array}$ & $\begin{array}{l}\text { Efficacy } \\
(N=2776)\end{array}$ \\
\hline Sex, male/female, $n$ & $1934 / 1331$ & $1643 / 1133$ \\
\hline $\begin{array}{l}\text { Age, years, } \\
\text { mean } \pm \mathrm{SD}\end{array}$ & $64.1 \pm 12.2$ & $64.0 \pm 12.1$ \\
\hline $\begin{array}{l}\text { BMI, } \mathrm{kg} / \mathrm{m}^{2}, \\
\text { mean } \pm \mathrm{SD}\end{array}$ & $25.19 \pm 4.45^{a}$ & $25.18 \pm 4.41^{\mathrm{b}}$ \\
\hline $\begin{array}{l}\text { HbAlc before start } \\
\text { of } \\
\text { administration, } \\
\% \text {, mean } \pm \text { SD }\end{array}$ & $7.96 \pm 1.47^{\mathrm{c}}$ & $7.92 \pm 1.46^{\mathrm{d}}$ \\
\hline \multicolumn{3}{|c|}{ Blood pressure, $\mathrm{mmHg}$, mean $\pm \mathrm{SD}$} \\
\hline Systolic & $133.7 \pm 16.5^{\mathrm{e}}$ & $133.8 \pm 16.4^{\mathrm{f}}$ \\
\hline Diastolic & $76.0 \pm 11.0^{\mathrm{g}}$ & $76.1 \pm 11.0^{\mathrm{h}}$ \\
\hline $\begin{array}{l}\text { LDL cholesterol, } \\
\text { mg/dL, } \\
\text { mean } \pm S D\end{array}$ & $115.6 \pm 31.6^{\mathrm{i}}$ & $115.7 \pm 31.3^{j}$ \\
\hline $\begin{array}{l}\text { eGFR before } \\
\text { administration, } \\
\mathrm{mL} / \mathrm{min} / \\
1.73 \mathrm{~m}^{2} \\
\text { mean } \pm \mathrm{SD}\end{array}$ & $77.75 \pm 22.22^{\mathrm{k}}$ & $78.21 \pm 21.16^{1}$ \\
\hline \multicolumn{3}{|l|}{ Complication, $n$} \\
\hline Hypertension & 1773 & 1508 \\
\hline Hyperlipidaemia & 1915 & 1643 \\
\hline Hyperuricemia & 265 & 218 \\
\hline $\begin{array}{l}\text { Diabetic } \\
\text { nephropathy }\end{array}$ & 518 & 428 \\
\hline $\begin{array}{l}\text { Diabetic } \\
\text { retinopathy }\end{array}$ & 258 & 211 \\
\hline $\begin{array}{l}\text { Diabetic } \\
\text { neuropathy }\end{array}$ & 276 & 224 \\
\hline \multicolumn{3}{|c|}{ Pretreatment drugs for T2DM, $n$} \\
\hline None & 1033 & 879 \\
\hline 1 drug & 1008 & 874 \\
\hline 2 drugs & 750 & 636 \\
\hline$\geq 3$ drugs & 459 & 373 \\
\hline Unknown & 15 & 14 \\
\hline
\end{tabular}

Table 1 continued

\begin{tabular}{lll}
\hline Background & Safety & Efficacy \\
characteristic & $(N=3265)$ & $(N=2776)$ \\
\hline
\end{tabular}

Type of pretreatment drugs for T2DM, $n$

$\begin{array}{lll}\text { None } & 1033 & 879 \\ \text { Sulfonylurea } & 1350 & 1144 \\ \text { Biguanide } & 915 & 783 \\ \begin{array}{l}\text { a-Glucosidase } \\ \text { inhibitor }\end{array} & 638 & 541 \\ \text { Thiazolidinedione } & 581 & 478 \\ \text { Fast-acting insulin } & 195 & 166 \\ \text { secretagogue } & & 136 \\ \text { Insulin } & 177 & \\ \text { preparation } & & 31 \\ \text { DPP4 inhibitor } & 46 & 5 \\ \text { SGLT2 inhibitor } & 6 & 2 \\ \text { GLP-1 receptor } & 3 & 14 \\ \text { agonists } & & \\ \text { Unknown/ } & 15 & \\ \text { unlisted } & & \end{array}$

Initial daily sitagliptin dose, $n$

$\begin{array}{lll}<50 \mathrm{mg} & 314 & 291 \\ 50 \mathrm{mg} & 2848 & 2485 \\ >50 \mathrm{mg} & 102 & 0 \\ \begin{array}{c}\text { Total sitagliptin } \\ \text { dose, mg, } \\ \text { mean } \pm \mathrm{SD}\end{array} & 40,888.6 \pm 24,935.4^{\mathrm{m}} & 41,386.8 \pm 23,016.4\end{array}$

Duration of administration, overall/monotherapy, $n$

$\begin{array}{lll}<3 \text { years } & 1896 / 633 & 1503 / 497 \\ \geq 3 \text { years } & 1364 / 413 & 1273 / 398 \\ \begin{array}{l}\text { Unknown/ } \\ \text { unlisted }\end{array} & 5 / 2 & 0 / 0 \\ \begin{array}{l}\text { Duration of } \\ \text { administration, }\end{array} & 772.5 \pm 404.0^{\mathrm{n}} & 808.3 \pm 395.2 \\ \begin{array}{l}\text { days, } \\ \text { mean } \pm \text { SD }\end{array} & & \end{array}$

Relationship between sitagliptin and pretreatment agent for T2DM, $n$

\begin{tabular}{lll} 
Naïve & 1033 & 879 \\
Switch & 974 & 802 \\
\hline
\end{tabular}


Table 1 continued

\begin{tabular}{lll}
\hline $\begin{array}{l}\text { Background } \\
\text { characteristic }\end{array}$ & $\begin{array}{l}\text { Safety } \\
(\boldsymbol{N}=\mathbf{3 2 6 5})\end{array}$ & $\begin{array}{l}\text { Efficacy } \\
(\boldsymbol{N}=\mathbf{2 7 7 6})\end{array}$ \\
\hline Add-on & 1243 & 1081 \\
Unknown & 15 & 14 \\
Usage at the start of administration, $n$ & \\
Single agent & 1326 & 1135 \\
Combination & 1926 & 1630 \\
Unknown & 13 & 11 \\
Concomitant T2DM medication during treatment with sitagliptin, $n$ \\
None & 1048 & 895 \\
Sulfonylurea & 1447 & 1230 \\
Biguanide & 1063 & 909 \\
Thiazolidinedione & 522 & 438 \\
a-Glucosidase & 451 & 386 \\
inhibitor & & 19 \\
Insulin & 164 & 123 \\
preparation & & 53 \\
Fast-acting insulin & 72 & \\
secretagogue & & 11 \\
SGLT2 inhibitor & 21 & \\
DPP4 inhibitor & 18 & \\
GLP-1 receptor & 5 & \\
agonists & & \\
Unknown/ & 13 & \\
\hline
\end{tabular}

$B M I$ body mass index, eGFR estimated glomerular filtration rate, HbAlc glycated haemoglobin, T2DM type 2 diabetes mellitus

$N$ values are those of overall safety or efficacy analysis set unless noted as follows: ${ }^{2} 2601 ;{ }^{\mathrm{b}} 2220 ;{ }^{\mathrm{c}} 2983 ;{ }^{\mathrm{d}} 2534 ;{ }^{\mathrm{e}} 2671 ;{ }_{2} 283$; ${ }^{\mathrm{g}} 2664 ;{ }^{\mathrm{h}} 2277$; iं2254; ${ }^{\mathrm{j}} 1906 ;{ }^{\mathrm{k}} 2399 ;{ }^{\mathrm{l}} 2024 ;{ }^{\mathrm{m}} 3259 ;{ }^{\mathrm{n}} 3260$

\section{Safety}

In the 3265 patients evaluated for safety, a total of 270 ADRs occurred in 207 (6.3\%) of patients overall. The numbers of patients with serious and non-serious ADRs according to MedDRA SOC categories are shown in Fig. 3. According to SOC categories, metabolic and nutritional disorders were the most common category of ADRs, occurring in 58 patients overall (53 non- serious, 5 serious). The most common serious ADRs occurred in the SOC categories of nervous system disorders and benign, malignant and unspecified neoplasms (8 patients each).

The incidence of ADRs of special interest are detailed in Table 2. Gastrointestinal disorders (40 patients, 1.23\%), hypoglycaemia (17 patients, $0.52 \%)$ and acute renal injury (16 patients, $0.49 \%$ ) were the most common of these ADRs, with hypoglycaemia and acute renal injury considered serious in two patients each. In the two serious cases of hypoglycaemia, one patient had received two concomitant antidiabetic agents and the other patient had received three or more concomitant antidiabetic agents at the time of onset. Of note, there were no cases of pemphigoid, severe skin disorders, acute pancreatitis, rhabdomyolysis, interstitial pneumonia and thrombocytopenia within the ADRs of special interest. Concomitant antidiabetic agents were sulfonylureas (both patients), as well as a biguanide, thiazolidinedione and insulin preparation (one patient each). Among these ADRs, cardiovascular events and various malignant tumours were the most common type of ADRs that were considered as serious [8 patients $(0.25 \%)$ for each]. Other types of serious ADRs occurred at low frequency $(<0.25 \%)$. It should be noted that there were no reported cases of acute pancreatitis, which is one of the more significant ADRs of special interest.

ADRs occurred most frequently within 12 months (121 patients, 3.7\%), of which 61 patients (1.9\%) experienced ADRs within 3 months. According to analysis by the Kaplan-Meier method, the cumulative incidence $(95 \%$ confidence interval) of patients with ADRs during the observation periods of within 12 months, within 24 months and within 36 months were $4.19 \%$ (3.53-4.97), $6.58 \% \quad(5.70-7.59)$ and $7.59 \% \quad(6.62-8.70)$, respectively. As shown in the Kaplan-Meier curve of the cumulative incidence of patients with ADRs, there was no apparent tendency for the onset of ADRs to be concentrated at a specific time or to increase over time (Fig. 4). The total listing of patients with ADRs in the safety analysis set according to time of onset is 


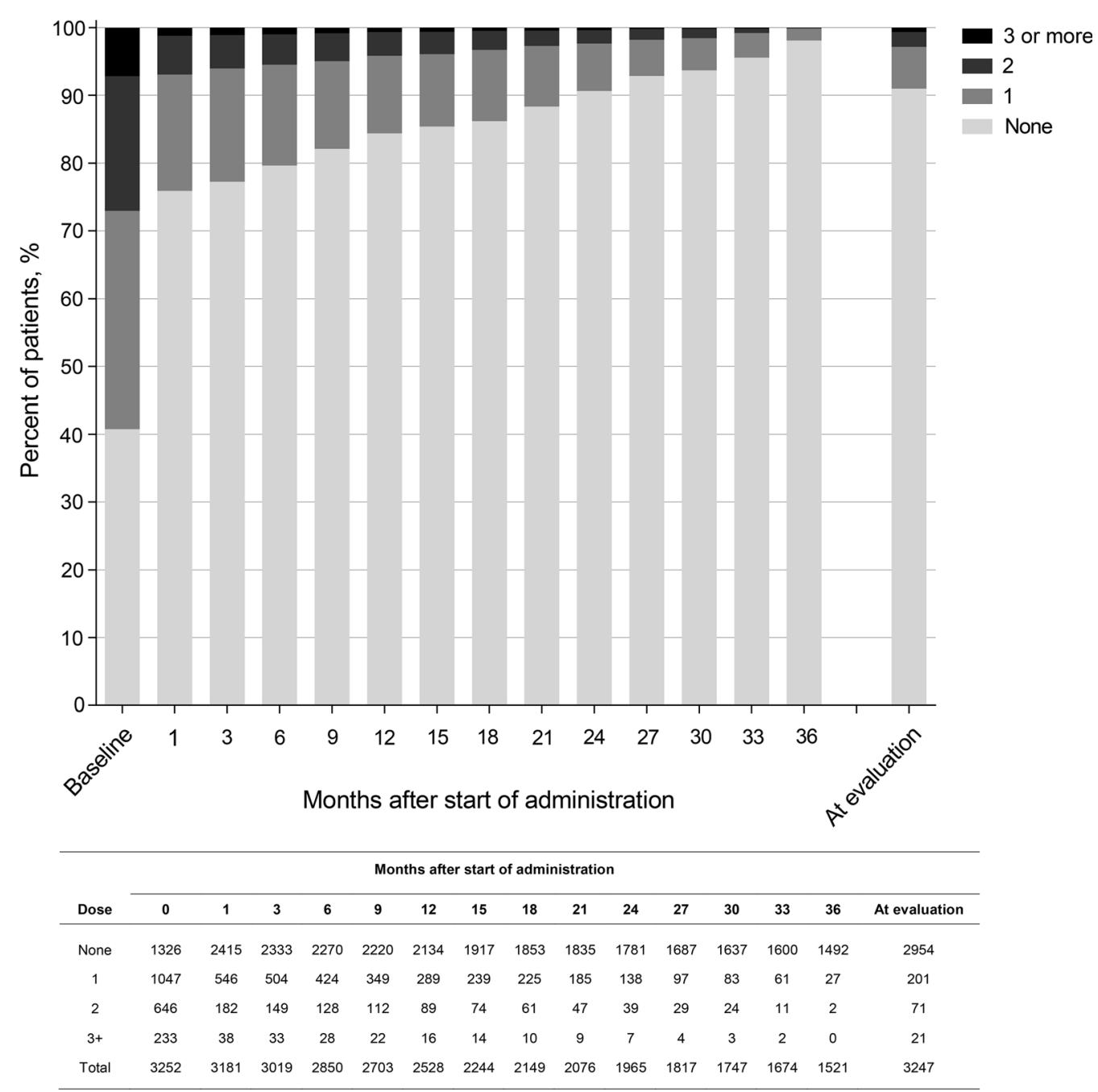

Fig. 2 Proportion of patients receiving concomitant antihyperglycaemic agents throughout observation period

shown in Table 1 of the electronic supplementary material.

The overall incidence of cardiovascular events in the total of 84 patients identified to be at high risk of prespecified cardiovascular events (cerebral infarction, subarachnoid haemorrhage or transient ischaemic attacks) was 4.76\% (4/84 patients). The cumulative incidence of patients with cardiovascular events throughout the observation period is shown in Fig. 5. Accordingly, the proportion of patients (95\% confidence interval of number at risk) with cardiovascular events at 12, 24 and 36 months was $1.20 \%(0.17-8.25 ; n=60)$ at 12 months, $3.18 \%(0.77-12.62 ; n=46)$ at 24 months and $8.42 \%(3.12-21.70 ; n=32)$ at 36 months, respectively. The frequency of cardiovascular events with sitagliptin administered during routine clinical practice in selected Japanese patients was not greater than with long-term addition of sitagliptin to usual care in patients with T2DM and established cardiovascular disease from outside of Japan [28].

Changes in eGFR for the overall population and according to eGFR category at the start of administration and by age for relevant patients are shown in Fig. 6. Patients with eGFR $\geq 90 \mathrm{~mL} / \mathrm{min} / 1.73 \mathrm{~m}^{2}$ had the greatest absolute decline in eGFR [mean \pm SD change from eGFR level before the start of administration $\left(106.42 \pm 18.11 \mathrm{~mL} / \mathrm{min} / 1.73 \mathrm{~m}^{2}, n=584\right)$ to the time of evaluation, $-11.83 \pm 17.53 \mathrm{~mL} /$ 


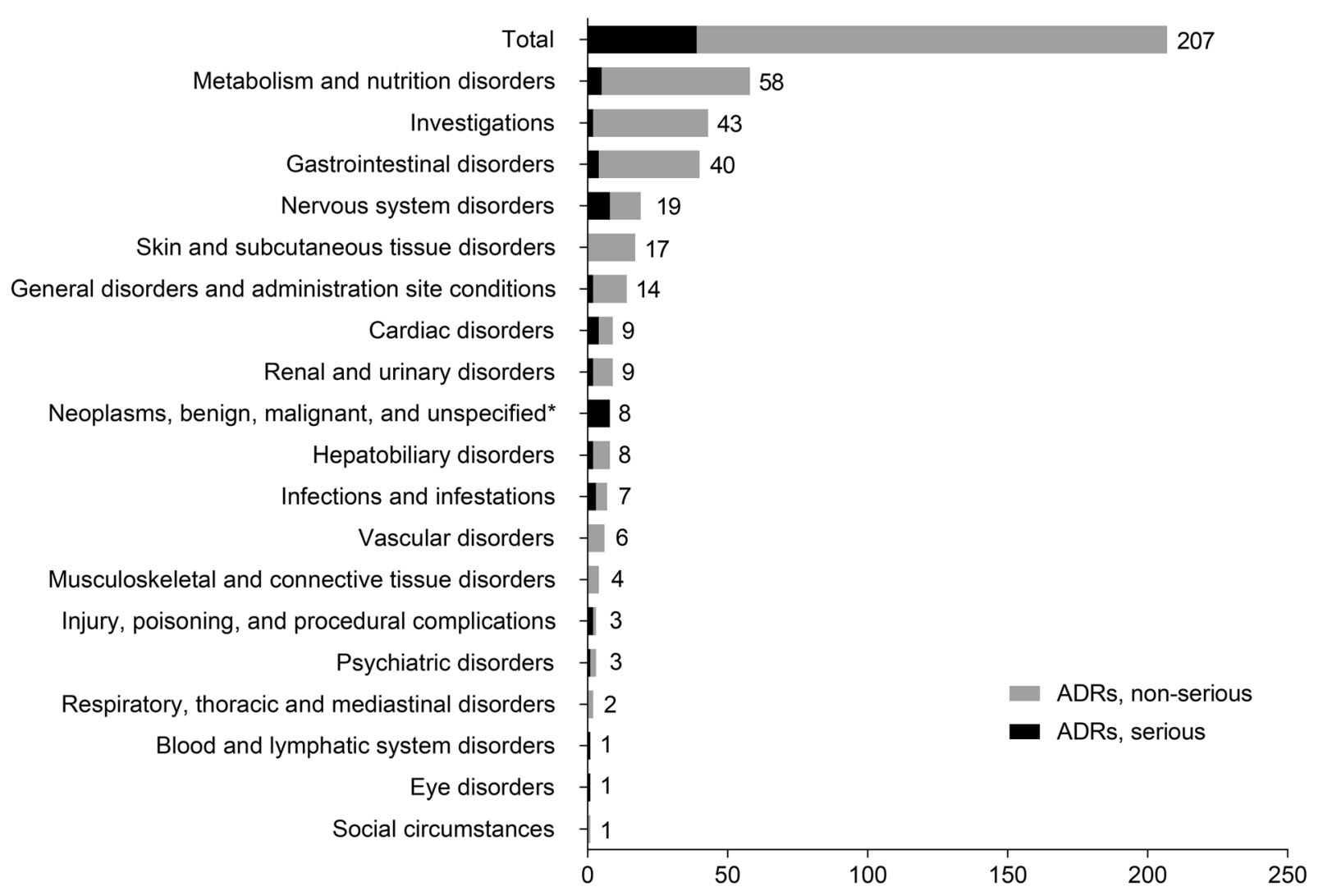

Fig. 3 Number of patients with serious and non-serious ADRs according to MedDRA SOC category. SOC system organ class. *Serious and non-serious cases in the same SOC were counted as serious

$\left.\min / 1.73 \mathrm{~m}^{2} ; \quad P<0.0001 ; \quad n=360\right] . \quad$ eGFR appeared to be relatively maintained in patients with $\mathrm{eGFR}<30 \mathrm{~mL} / \mathrm{min} / 1.73 \mathrm{~m}^{2}$ [mean $\pm \mathrm{SD}$ change from eGFR level before the start of administration $\left(24.57 \pm 5.64 \mathrm{~mL} / \mathrm{min} / 1.73 \mathrm{~m}^{2}\right.$, $n=21$ ) to the time of evaluation, $+0.30 \pm 20.00 \mathrm{~mL} / \mathrm{min} / 1.73 \mathrm{~m}^{2} ; \quad P=0.9491$; $n=19$ ]. However, the relative decline in eGFR from start of administration to the time of evaluation was similar among the age groups (approximately 6.0-6.5\% relative decrease).

\section{Efficacy}

Among patients included in the efficacy analysis set, HbA1c decreased from 1 month after the start of administration and the effect continued throughout and after the administration period of 36 months to the final evaluation (Fig. 7a). For the whole population, the change in HbA1c from baseline level (mean \pm SD, $7.92 \pm 1.46 \%$; $n=2534)$ to final evaluation was mean \pm SD $-0.68 \pm 1.34 \% \quad(P<0.0001, \quad n=2070)$. Patients who received sitagliptin as monotherapy showed a similar change in HbA1c from baseline level (mean \pm SD, $7.60 \pm 1.43 \%$; $n=1003$ ) to final evaluation (mean \pm SD change $-0.66 \pm 1.27 \%, P<0.0001, n=801)$. Similarly, HbA1c decreased in all patients who were stratified according to BMI and age albeit to different degrees (Fig. 7b, c). The change in HbA1c at the final evaluation tended to be greater among patients with medium (18.5 to $\left.<25.0 \mathrm{~kg} / \mathrm{m}^{2}\right)$ or high $\left(\geq 25.0 \mathrm{~kg} / \mathrm{m}^{2}\right)$ BMI values compared with patients with low BMI $\left(<18.5 \mathrm{~kg} / \mathrm{m}^{2}\right)$. The changes in HbA1c from baseline levels of $7.79 \pm 1.40 \% \quad(n=1055)$, $8.11 \pm 1.51 \% \quad(n=954) \quad$ and $\quad 7.55 \pm 1.15 \%$ $(n=74) \quad$ were $\quad$ mean \pm SD $\quad-0.69 \pm 1.27 \%$ $(n=879), \quad-0.72 \pm 1.49 \% \quad(n=796) \quad$ and $-0.39 \pm 1.13 \% \quad(n=56)$ for patients with medium, high and low BMI values, respectively. 
Table 2 Number of patients with ADRs of special interest

\begin{tabular}{|c|c|c|c|c|c|}
\hline & $\begin{array}{l}\text { Overall, } \\
n(\%)\end{array}$ & $\begin{array}{l}\text { Serious, } \\
n(\%)\end{array}$ & Type of ADR (MedDRA PT) & $\begin{array}{l}\text { Overall, } \\
n(\%)\end{array}$ & $\begin{array}{l}\text { Serious, } \\
n(\%)\end{array}$ \\
\hline \multirow[t]{4}{*}{ Cardiovascular event $^{a}$} & $8(0.25)$ & $8(0.25)$ & Acute myocardial infarction & $1(0.03)$ & $1(0.03)$ \\
\hline & & & Angina pectoris & $1(0.03)$ & $1(0.03)$ \\
\hline & & & Unstable angina & $1(0.03)$ & $1(0.03)$ \\
\hline & & & Cerebral infarction & $5(0.15)$ & $5(0.15)$ \\
\hline \multirow[t]{7}{*}{ Malignant tumour $^{a}$} & $8(0.25)$ & $8(0.25)$ & Acute myeloid leukaemia & $1(0.03)$ & $1(0.03)$ \\
\hline & & & Cervical cancer & $1(0.03)$ & $1(0.03)$ \\
\hline & & & Colon cancer & $1(0.03)$ & $1(0.03)$ \\
\hline & & & Gastric cancer & $2(0.06)$ & $2(0.06)$ \\
\hline & & & Pancreatic cancer & $1(0.03)$ & $1(0.03)$ \\
\hline & & & Renal cancer & $1(0.03)$ & $1(0.03)$ \\
\hline & & & Malignant lung neoplasm & $1(0.03)$ & $1(0.03)$ \\
\hline \multirow[t]{2}{*}{ Hypoglycaemia $^{a}$} & $17(0.52)$ & $2(0.06)$ & Hypoglycaemia & $17(0.52)$ & $2(0.06)$ \\
\hline & & & Hypoglycaemic unconsciousness & $1(0.03)$ & $1(0.03)$ \\
\hline \multirow[t]{7}{*}{ Acute renal injury ${ }^{a}$} & $16(0.49)$ & $2(0.06)$ & Increased blood creatinine & $4(0.12)$ & $0(0.00)$ \\
\hline & & & Microalbuminuria & $1(0.03)$ & $0(0.00)$ \\
\hline & & & Albuminuria & $1(0.03)$ & $0(0.00)$ \\
\hline & & & Renal failure & $1(0.03)$ & $1(0.03)$ \\
\hline & & & Urine protein positive & $4(0.12)$ & $0(0.00)$ \\
\hline & & & $\begin{array}{l}\text { Increased urinary albumin/creatinine } \\
\text { ratio }\end{array}$ & $1(0.03)$ & $0(0.00)$ \\
\hline & & & Renal dysfunction & $5(0.15)$ & $1(0.03)$ \\
\hline \multirow[t]{3}{*}{ Hepatic dysfunction and jaundice ${ }^{a}$} & $7(0.21)$ & $1(0.03)$ & Abnormal liver function & $5(0.15)$ & $0(0.00)$ \\
\hline & & & Hepatic disorder & $1(0.03)$ & $0(0.00)$ \\
\hline & & & Drug-induced liver injury & $1(0.03)$ & $1(0.03)$ \\
\hline Anaphylaxis and angioedema ${ }^{a}$ & $1(0.03)$ & $0(0.00)$ & Urticaria & $1(0.03)$ & $0(0.00)$ \\
\hline \multirow[t]{2}{*}{ Ileus $^{a}$} & $2(0.06)$ & $1(0.03)$ & Small bowel obstruction & $1(0.03)$ & $1(0.03)$ \\
\hline & & & Intestinal scar & $1(0.03)$ & $0(0.00)$ \\
\hline \multirow[t]{17}{*}{ Gastrointestinal disorder ${ }^{a}$} & $40(1.23)$ & $4(0.12)$ & Abdominal discomfort & $3(0.09)$ & $0(0.00)$ \\
\hline & & & Abdominal distension & $5(0.15)$ & $0(0.00)$ \\
\hline & & & Abdominal mass & $1(0.03)$ & $1(0.03)$ \\
\hline & & & Abdominal pain & $2(0.06)$ & $0(0.00)$ \\
\hline & & & Constipation & $15(0.46)$ & $0(0.00)$ \\
\hline & & & Diarrhoea & $1(0.03)$ & $0(0.00)$ \\
\hline & & & Duodenal ulcer & $1(0.03)$ & $1(0.03)$ \\
\hline & & & Dysphagia & $1(0.03)$ & $0(0.00)$ \\
\hline & & & Gastric ulcer & $1(0.03)$ & $1(0.03)$ \\
\hline & & & Gastro-oesophageal reflux disease & $4(0.12)$ & $0(0.00)$ \\
\hline & & & Nausea & $4(0.12)$ & $0(0.00)$ \\
\hline & & & Pancreatic cyst & $1(0.03)$ & $0(0.00)$ \\
\hline & & & Small bowel obstruction & $1(0.03)$ & $1(0.03)$ \\
\hline & & & Stomatitis & $2(0.06)$ & $0(0.00)$ \\
\hline & & & Vomiting & $3(0.09)$ & $0(0.00)$ \\
\hline & & & Polyp of colon & $1(0.03)$ & $0(0.00)$ \\
\hline & & & Intestinal scar & $1(0.03)$ & $0(0.00)$ \\
\hline
\end{tabular}


Table 2 continued

\begin{tabular}{|c|c|c|c|c|c|}
\hline & $\begin{array}{l}\text { Overall, } \\
n(\%)\end{array}$ & $\begin{array}{l}\text { Serious, } \\
n(\%)\end{array}$ & Type of ADR (MedDRA PT) & $\begin{array}{l}\text { Overall, } \\
n(\%)\end{array}$ & $\begin{array}{l}\text { Serious, } \\
n(\%)\end{array}$ \\
\hline \multirow{4}{*}{$\begin{array}{l}\text { Musculoskeletal and connective tissue } \\
\text { disorders }\end{array}$} & \multirow[t]{4}{*}{$4(0.12)$} & \multirow[t]{4}{*}{$0(0.00)$} & Backache & $1(0.03)$ & $0(0.00)$ \\
\hline & & & Inguinal pain & $1(0.03)$ & $0(0.00)$ \\
\hline & & & Osteoporosis & $1(0.03)$ & $0(0.00)$ \\
\hline & & & Stenotic tenosynovitis & $1(0.03)$ & $0(0.00)$ \\
\hline \multirow[t]{9}{*}{ Infectious disease $^{\mathrm{b}}$} & \multirow[t]{9}{*}{$7(0.21)$} & \multirow[t]{9}{*}{$3(0.09)$} & Bronchitis & $1(0.03)$ & $0(0.00)$ \\
\hline & & & Diverticulitis & $1(0.03)$ & $1(0.03)$ \\
\hline & & & Gastroenteritis & $1(0.03)$ & $0(0.00)$ \\
\hline & & & Osteomyelitis & $1(0.03)$ & $1(0.03)$ \\
\hline & & & Otitis externa & $1(0.03)$ & $1(0.03)$ \\
\hline & & & Otitis media & $1(0.03)$ & $0(0.00)$ \\
\hline & & & Periodontitis & $1(0.03)$ & $0(0.00)$ \\
\hline & & & Pneumonia & $1(0.03)$ & $1(0.03)$ \\
\hline & & & Urinary tract infection & $1(0.03)$ & $0(0.00)$ \\
\hline
\end{tabular}

PT Preferred Term, SOC System Organ Class (MedDRA/J version 20.0)

a Standardised MedDRA Queries (SMQs) were used in the identification and retrieval of potentially relevant reactions

b MedDRA SOC category was used in the identification and retrieval of potentially relevant reactions (excluding acute pancreatitis and bowel obstruction)

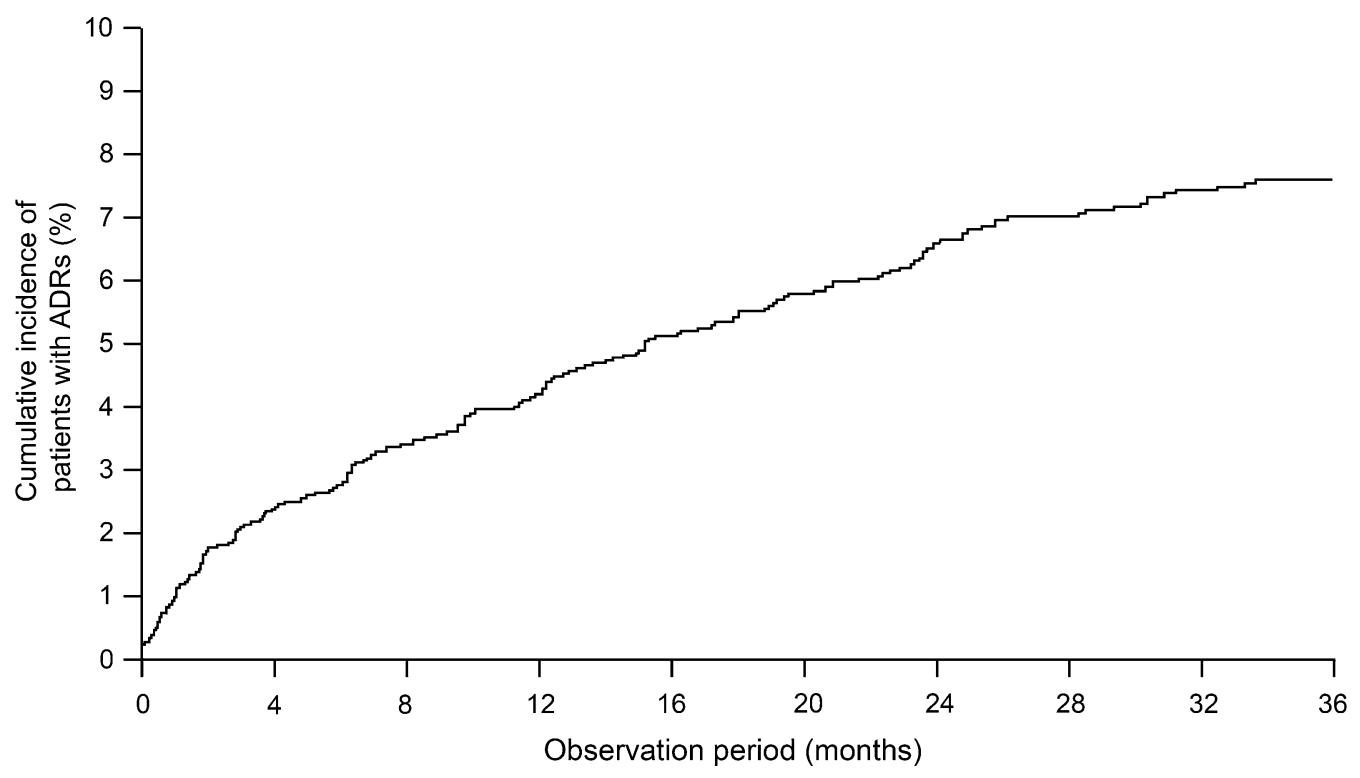

Fig. 4 Cumulative incidence of patients with ADRs over the 36-month observation period in the safety analysis set by Kaplan-Meier method

Elderly patients (age $\geq 75$ years) had lower changes in HbA1c than patients aged 65 to $<75$ years and in patients aged 15 to $<65$ years. This was reflected in the lower change from baseline level $(7.49 \pm 1.09 \%, n=514)$ at final evaluation in patients with age $\geq 75$ years (mean \pm SD change $-0.52 \pm 0.89 \%, \quad P<$ $0.0001, n=411)$ than in patients aged 65 to $<75$ years (baseline level $7.76 \pm 1.29 \%$, $n=747$; mean \pm SD change $-0.61 \pm 1.20 \%$, 


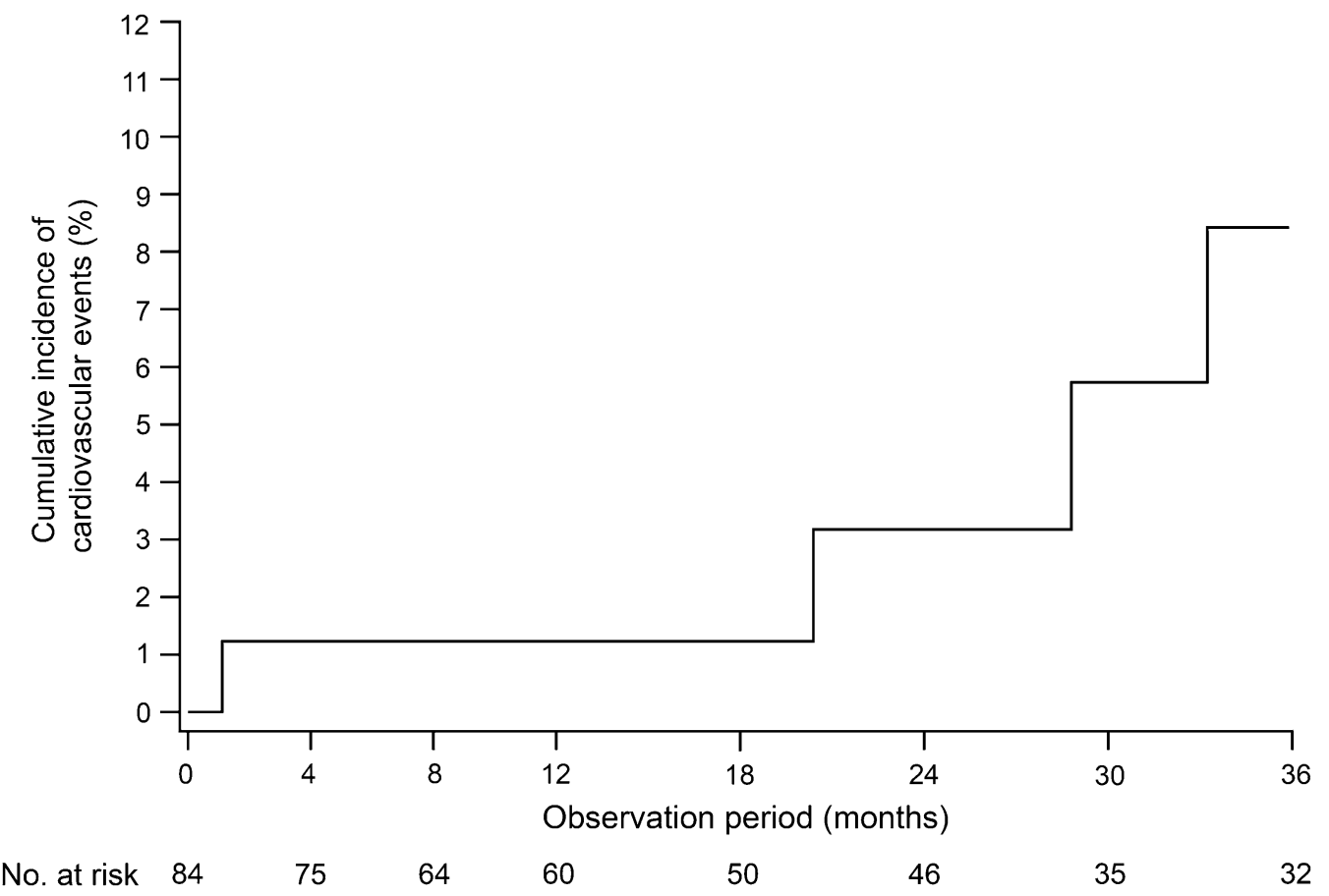

Fig. 5 Kaplan-Meier plot of cumulative incidence of patients with cardiovascular events (high-risk population). Only serious adverse events shown

$P<0.0001, n=638$ ) and patients aged 15 to $<65$ years (baseline level $8.19 \pm 1.61 \%$, $n=1273$; mean \pm SD change $-0.79 \pm 1.56 \%$, $P<0.0001, n=1021)$. Finally, the reduction in HbA1c was statistically significant among patients with $\mathrm{HbA} 1 \mathrm{c}$ levels at baseline of $7.0 \%$ to $<8.0 \%$ and $\geq 8.0 \% \quad(P<0.0001$ for both; $n=287$ and $n=266$, respectively) compared with the group of patients with HbA1c levels $6.0 \%$ to $<7.0 \% \quad(P=0.1034 ; n=214)$ and $<6.0 \%(P=0.0424 ; n=18)$, in which a small increase in HbA1c was noted.

\section{DISCUSSION}

In accordance with Japanese regulatory requirements, this PMS evaluated the ongoing safety and efficacy of sitagliptin treatment in Japanese patients with T2DM in a real-world condition. Patients enrolled in this long-term survey were generally older, with elevated HbA1c, reduced eGFR levels and frequent comorbidities, particularly hypertension and hyperlipidaemia, and can thus be considered representative of Japanese patients with T2DM in routine clinical practice. Despite the fact that T2DM is a progressive disease, the proportion of patients treated with one or more concomitant antihyperglycaemic agents reduced substantially as early as 1 month after the start of sitagliptin administration from $59.2 \%$ of patients at baseline and continued to decrease throughout the observation period to $1.9 \%$ of patients at final evaluation. Accordingly, the potentially confounding effects of other antihyperglycaemic medications on these results can be considered to be relatively limited.

The results of the safety analysis demonstrate that sitagliptin is generally well tolerated with routine long-term use. Overall, ADRs occurred at a relatively low frequency in this PMS and the overall frequency of ADRs of special interest during the observation period $(0.86 \%$ of patients) is consistent with the results of previous clinical trials of sitagliptin in Japanese patients, in which the frequency of serious ADRs was typically less than $1.0 \%$ $[15,17-19,22,23]$. In accordance with the known safety profile of sitagliptin, 

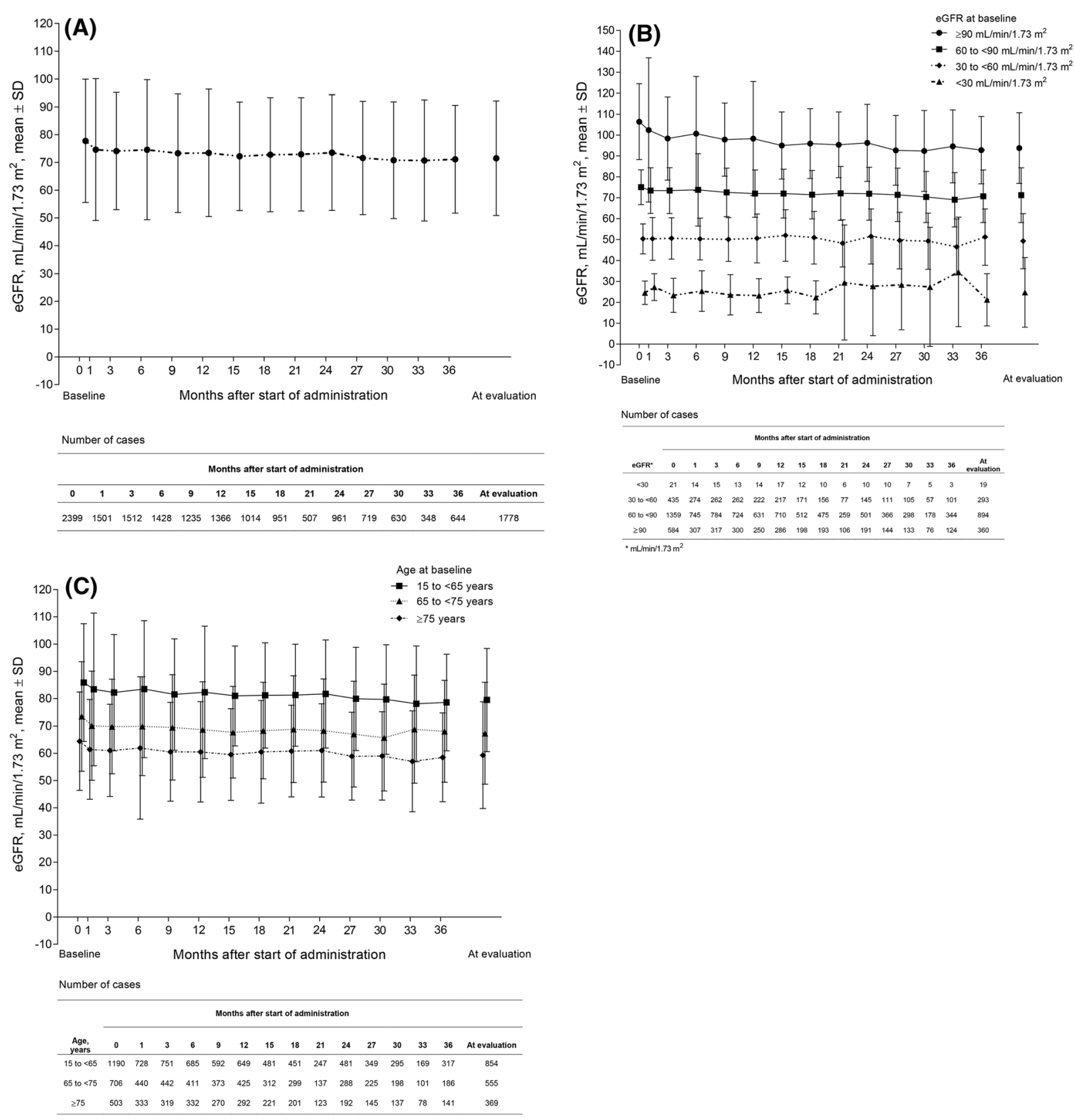

Fig. 6 Change in eGFR over the administration period a overall and for populations stratified by $\mathbf{b}$ eGFR at baseline and c age

hypoglycaemia was the most common specific ADR noted with long-term use. ADRs were generally either not concentrated at a specific time or tended to occur most frequently early in the administration period after which the incidence did not increase over time. Data in relation to cardiovascular events is also a particularly important aspect of this long-term survey given that Japanese patients were not included in studies, such as the large-scale TECOS study [28], in which sitagliptin did not appear to increase the risk of major adverse cardiovascular events, including hospitalization for heart failure, compared with placebo during median follow-up of 3 years. Using selection criteria similar to TECOS, these long-term 

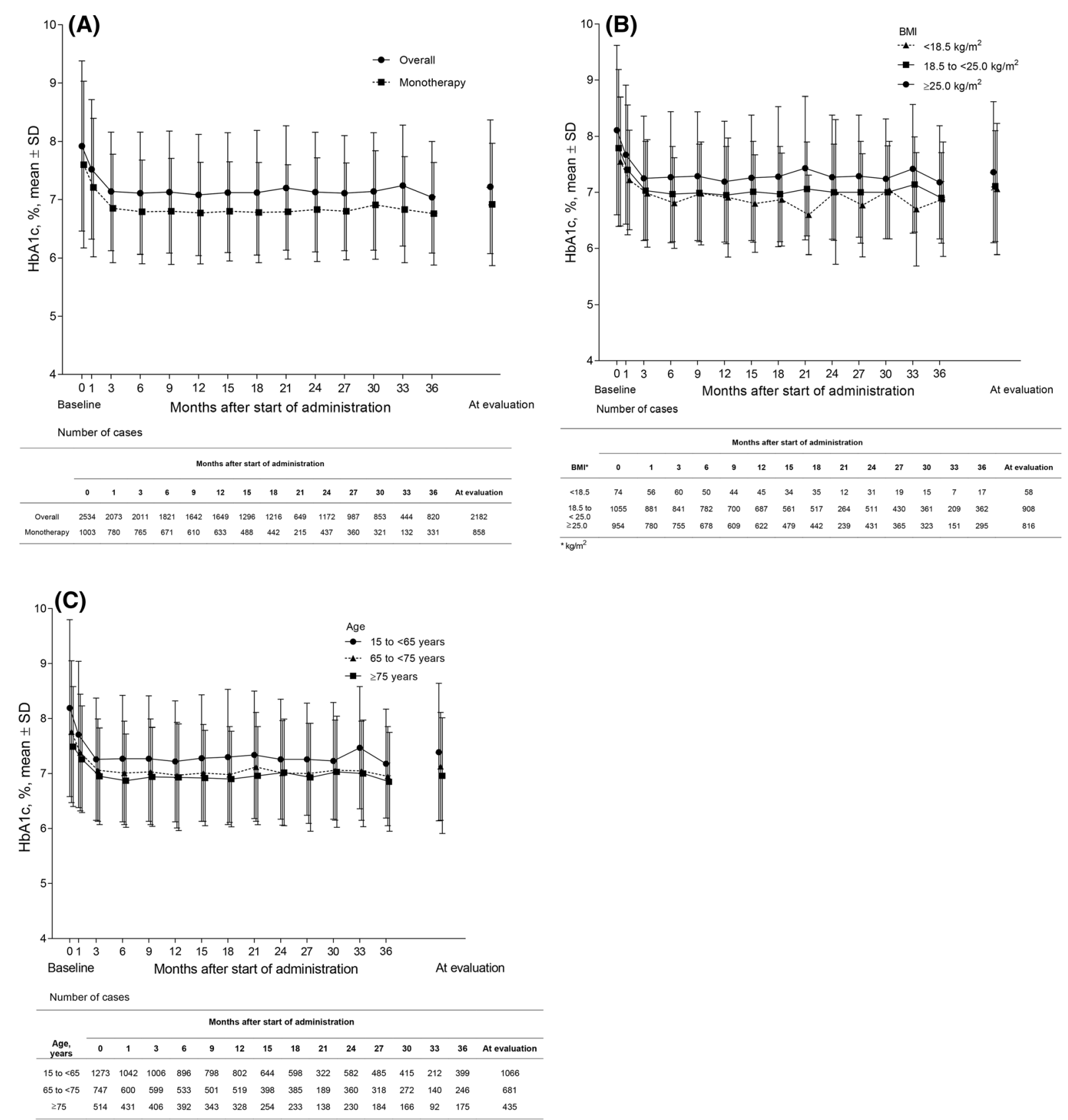

Fig. $7 \mathrm{HbAlc}$ over administration period for a overall efficacy analysis set and stratified by $\mathbf{b}$ BMI and $\mathbf{c}$ age

results in Japanese patients did not demonstrate any additional concerns in relation to increased risk of cardiovascular events. In terms of renal function, eGFR at baseline was generally maintained throughout the 3-year observation period of this PMS, including in patients with lower eGFR levels at baseline. An apparent initial decrease in eGFR was seen after the start of sitagliptin administration and this was particularly noticeable among the subgroup of patients with higher eGFR levels at baseline. Glomerular hyperfiltration has been commonly noted in patients with T2DM, especially early in the course of disease when patients most likely have at least near-normal renal functional reserves. The pathogenesis of glomerular hyperfiltration 
is complex although hyperglycaemia is thought to play a prominent role, especially in early diabetes [29]. In terms of specific mechanisms, the tubular theory proposes that enhanced proximal tubular sodium/glucose reabsorption, associated with upregulation of sodium-glucose cotransporters and sodium/hydrogen exchanger reduces afferent arteriolar resistance and the increase in single-nephron GFR through inhibition of tubuloglomerular feedback (TGF). Although hypothetical, an initial reduction in eGFR seen in patients overall and particularly those with eGFR $>90 \mathrm{~mL} / \mathrm{min} / 1.73 \mathrm{~m}^{2}$ in this PMS may relate to redress of glomerulus hyperfiltration associated with improvement in hyperglycaemia and possibly direct effects of DPP4 enzyme inhibition on TGF, which have been proposed in the literature [29]. Overall, the safety results of this PMS provide reassurance that sitagliptin, when used in routine clinical practice in Japanese patients, concurs with expectations and raises no additional safety concerns.

In terms of efficacy, results from this PMS are also generally consistent with results noted in previous clinical trials and in longer-term observational studies. In a number of comparative clinical trials conducted in Japan, sitagliptin administered at standard doses led to reductions in $\mathrm{HbA} 1 \mathrm{c}$ of approximately $0.7-0.9 \%$ compared with placebo when added to diet and exercise either alone or in combination with other agents (e.g. insulin monotherapy, pioglitazone, glimepiride) $[19,21,22]$. Of greater relevance, reductions in HbA1c in this PMS are similar to those noted in longer-term observational studies. For example, in an open-label, observational study of 164 outpatients with T2DM, HbA1c reduced by $0.8 \%$ at 3 months and 6 months [30]. In the previously mentioned retrospective, cohort study of 3427 outpatients, addition of sitagliptin to diet and exercise, oral hypoglycaemic agents and/or insulin therapy led to reductions in HbA1c of approximately $0.7 \%$ at 6 months [25]. This result is highly consistent with that of the overall population in the present PMS, in which HbA1c reduced by $0.68 \%$ over 36 months. As noted previously, it is worthwhile noting that these positive results were obtained despite sitagliptin being used as antihyperglycaemic monotherapy in the majority of patients from 1 month after the start of administration onwards. From another perspective, sitagliptin was able to maintain glycaemic control while greatly reducing the number of concomitant medications in this population.

Limitations of this non-interventional, observational PMS include the lack of an independent control group of non-sitagliptin-treated patients and inclusion of a relatively small number of parameters compared with those utilized in clinical studies and some observational studies. On the other hand, the study population in this PMS was large and also reflects that seen in clinical practice with a relative lack of selection bias compared with other trial types. A specific limitation of this PMS relates to the small number of patients with low eGFR values $\left(<30 \mathrm{~mL} / \mathrm{min} / 1.73 \mathrm{~m}^{2}\right)$ or low BMI $\left(<18.5 \mathrm{mg} / \mathrm{kg}^{2}\right)$, in which these results should be interpreted more cautiously.

\section{CONCLUSION}

Results of this long-term and large-scale PMS indicate that sitagliptin usage patterns as well as expected safety and efficacy are similar between real-world treatment conditions and those associated with previous clinical trials and observational studies. Further, sitagliptin was able to maintain effective glycaemic control while reducing the number of concomitant medications in association with a low frequency of drug-related adverse reactions. In particular, concerns related to potential risks associated with long-term use, such as pancreatitis, cardiovascular events and decreased renal function, did not emerge, which demonstrates the safety and tolerability of long-term use of sitagliptin in Japanese patients with T2DM.

\section{ACKNOWLEDGEMENTS}

The authors thank all clinicians for their involvement and contribution to the surveillance. 
Funding. This study and the journal's Rapid Service and Open Access Fees were funded by Ono Pharmaceuticals and MSD K.K., Tokyo, Japan.

Medical Writing Assistance. The authors also thank Mark Snape, MBBS, CMPP of inScience Communications, Springer Healthcare, for writing the outline and the first draft of the manuscript. This medical writing assistance was funded by Ono Pharmaceuticals and MSD K.K., Tokyo, Japan.

Authorship. All named authors meet the International Committee of Medical Journal Editors (ICMJE) criteria for authorship for this article, take responsibility for the integrity of the work as a whole, and have given their approval for this version to be published.

Author Contributions. Yoshikazu Maeda contributed in conception and design of the study. Akira Tsuchiya, Tomohiro Ota, Keiko Ikeda and Mika Iwakura contributed in acquisition of data. Tomohiro Ota, Keiko Ikeda, Mika Iwakura and Yoshikazu Maeda contributed in data analysis. Ken Yoshikawa, Tomoyuki Kido, Tomohiro Ota, Keiko Ikeda, Yoshikazu Maeda and Shinichiroh Maekawa contributed in data interpretation.

Disclosures. Ken Yoshikawa, Akira Tsuchiya and Tomoyuki Kido are employees of Ono Pharmaceutical Co., Ltd. Tomohiro Ota, Keiko Ikeda, Mika Iwakura, Yoshikazu Maeda and Shinichiroh Maekawa are employees of MSD K.K., Tokyo, Japan.

Compliance with Ethics Guidelines. This study was conducted as a multicentre, open-label, prospective, non-interventional study in accordance with the Ministerial Ordinance on Good Post-Marketing Study Practice (Ministry of Health, Labour and Welfare Ordinance No. 171, December 20, 2004). The study protocol was reviewed and approved by the Japanese regulatory authority before initiation. According to the Japanese standards for conducting PMS, this activity was not required to undergo review by the ethics committee of the participating medical institutions or procedures for informed consent unless such procedures were required by individual participating medical institutions.

Data Availability. Qualified researchers may request study sponsors to disclose individual patient-level data from clinical studies through the data sharing platforms. However, the datasets generated during and/or analysed during the current study are not publicly available because they do not meet the criteria of the sponsors' policies for the disclosure of clinical study data.

Open Access. This article is licensed under a Creative Commons Attribution-NonCommercial 4.0 International License, which permits any non-commercial use, sharing, adaptation, distribution and reproduction in any medium or format, as long as you give appropriate credit to the original author(s) and the source, provide a link to the Creative Commons licence, and indicate if changes were made. The images or other third party material in this article are included in the article's Creative Commons licence, unless indicated otherwise in a credit line to the material. If material is not included in the article's Creative Commons licence and your intended use is not permitted by statutory regulation or exceeds the permitted use, you will need to obtain permission directly from the copyright holder. To view a copy of this licence, visit http:// creativecommons.org/licenses/by-nc/4.0/.

\section{REFERENCES}

1. Ministry of Health, Labour, and Welfare. National Health and Nutrition Survey (2012). https://www. mhlw.go.jp/stf/houdou/0000032074.html. Accessed 26 July 2019.

2. Ministry of Health, Labour, and Welfare. National Health and Nutrition Survey (2016). https://www. mhlw.go.jp/stf/houdou/0000177189.html. Accessed 26 July 2019. 
3. Goto $A$, Noda $M$, Inoue $M$, Goto $M$, Charvat $H$. Increasing number of people with diabetes in Japan: is this trend real? Intern Med. 2016;55:1827-30.

4. Murakami K, Livingstone MBE, Sasaki S. Thirteenyear trends in dietary patterns among Japanese adults in the national health and nutrition survey 2003-2015: continuous westernization of the Japanese diet. Nutrients. 2018;10:994.

5. Khalil H. Diabetes microvascular complications-a clinical update. Diabetes Metab Syndr. 2017;11(Suppl 1):S133-9.

6. Paneni F, Luscher TF. Cardiovascular protection in the treatment of type 2 diabetes: a review of clinical trial results across drug classes. Am J Cardiol. 2017;120:S17-27.

7. Leal J, Gray AM, Clarke PM. Development of lifeexpectancy tables for people with type 2 diabetes. Eur Heart J. 2009;30:834-9.

8. Trikkalinou A, Papazafiropoulou AK, Melidonis A. Type 2 diabetes and quality of life. World J Diabetes. 2017;8:120-9.

9. UK Prospective Diabetes Study (UKPDS) Group. Intensive blood-glucose control with sulphonylureas or insulin compared with conventional treatment and risk of complications in patients with type 2 diabetes (UKPDS 33). Lancet. 1998;352: 837-53.

10. Gerstein HC, Miller ME, Action to Control Cardiovascular Risk in Diabetes Study Group, et al. Effects of intensive glucose lowering in type 2 diabetes. N Engl J Med. 2008;358:2545-59.

11. Patel A, MacMahon S, Advance Collaborative Group, et al. Intensive blood glucose control and vascular outcomes in patients with type 2 diabetes. N Engl J Med. 2008;358:2560-72.

12. Holman RR, Paul SK, Bethel MA, Matthews DR, Neil HA. 10-year follow-up of intensive glucose control in type 2 diabetes. N Engl J Med. 2008;359:1577-89.

13. Knowler WC, Barrett-Connor E, Fowler SE, et al. Reduction in the incidence of type 2 diabetes with lifestyle intervention or metformin. N Engl J Med. 2002;346:393-403.

14. Inzucchi SE. Oral antihyperglycemic therapy for type 2 diabetes: scientific review. JAMA. 2002;287: 360-72.

15. Terauchi Y, Yamada Y, Ishida H, et al. Efficacy and safety of sitagliptin as compared with glimepiride in Japanese patients with type 2 diabetes mellitus aged $\geq 60$ years (START-J trial). Diabetes Obes Metab. 2017;19:1188-92.
16. Nishimura R, Kato H, Kisanuki K, et al. Treatment patterns, persistence and adherence rates in patients with type 2 diabetes mellitus in Japan: a claims-based cohort study. BMJ Open. 2019;9: e025806.

17. Iwamoto Y, Tajima N, Kadowaki T, et al. Efficacy and safety of sitagliptin monotherapy compared with voglibose in Japanese patients with type 2 diabetes: a randomized, double-blind trial. Diabetes Obes Metab. 2010;12:613-22.

18. Iwamoto $\mathrm{Y}$, Taniguchi $\mathrm{T}$, Nonaka $\mathrm{K}$, et al. Doseranging efficacy of sitagliptin, a dipeptidyl peptidase-4 inhibitor, in Japanese patients with type 2 diabetes mellitus. Endocr J. 2010;57:383-94.

19. Kadowaki T, Tajima N, Odawara M, et al. Efficacy and safety of sitagliptin add-on therapy in Japanese patients with type 2 diabetes on insulin monotherapy. Diabetol Int. 2013;4:160-72.

20. Kadowaki T, Tajima N, Odawara M, et al. Addition of sitagliptin to ongoing metformin monotherapy improves glycemic control in Japanese patients with type 2 diabetes over 52 weeks. J Diabetes Investig. 2013;4:174-81.

21. Kashiwagi A, Kadowaki T, Tajima N, et al. Sitagliptin added to treatment with ongoing pioglitazone for up to 52 weeks improves glycemic control in Japanese patients with type 2 diabetes. J Diabetes Investig. 2011;2:381-90.

22. Tajima N, Kadowaki T, Odawara M, et al. Addition of sitagliptin to ongoing glimepiride therapy in Japanese patients with type 2 diabetes over 52 weeks leads to improved glycemic control. Diabetol Int. 2011;2:32-44.

23. Tajima N, Kadowaki T, Okamoto T, et al. Sitagliptin added to voglibose monotherapy improves glycemic control in patients with type 2 diabetes. J Diabetes Investig. 2013;4:595-604.

24. Ohmura H, Mita T, Matsuoka J, et al. Real-world data on the incidence of macrovascular complications in Japanese patients with type 2 diabetes: the sitagliptin registration type 2 diabetes-juntendo collaborating project. Diabetes Ther. 2019;10: 1099-111.

25. Ohmura H, Mita T, Taneda Y, et al. Efficacy and safety of sitagliptin in Japanese patients with type 2 diabetes. J Clin Med Res. 2015;7:211-9.

26. Haque A, Daniel S, Maxwell T, Boerstoel M. Postmarketing surveillance studies-an industry perspective on changing global requirements and implications. Clin Ther. 2017;39:675-85. 
27. Ministry of Health, Labour and Welfare. Good postmarketing study practice [GPSP Ministerial Ordinance of Drugs] [Japan]. December 20, 2004.

28. Green JB, Bethel MA, Armstrong PW, et al. Effect of sitagliptin on cardiovascular outcomes in type 2 diabetes. N Engl J Med. 2015;373:232-42.

29. Tonneijck L, Muskiet MH, Smits MM, et al. Glomerular hyperfiltration in diabetes: mechanisms, clinical significance, and treatment. J Am Soc Nephrol. 2017;28:1023-39.

30. Tajiri Y, Tsuruta M, Ohki T, et al. Long-term efficacy of sitagliptin for the treatment of type 2 diabetic patients in Japan. Endocr J. 2012;59:197-204. 